\title{
PENDAMPINGAN PEMBUATAN PODCAST KREATIF MELALUI SENI BERKOMUNIKASI EFEKTIF DI SMA KARYA ENAM-ENAM JAKARTA
}

\author{
Djudjur Luciana Radjagukguk ${ }^{1}$,Yayu Sriwartini ${ }^{2}$, Agus Salim $^{3}$ \\ Fakultas Ilmu Sosial Dan Ilmu Politik, Program Studi Ilmu Komunikasi, Universitas Nasional ${ }^{123}$ \\ djudjurluciana01@gmail.com, yayu_sriwartini@yahoo.com, agussalim.unas21@gmail.com
}

\begin{abstract}
ABSTRAK
Podcast berkembang sangat cepat, laporan terbaru untuk kuartal-II 2019 menjelaskan layanan streaming musik spotify menyebutkan bahwa jumlah pendengar podcast tumbuh lebih dari 50 persen dari kuartal sebelumnya. Pada pelajar SMA podcast menjadi tempat untuk menyalurkan bakat terutama dalam bidang public speaking dan content creator, terlebih pada masa pandemi.. Media digital satu ini memang sedang marak digunakan di berbagai kalangan dari segala usia, dengan memilih beberapa konten untuk dijadikan sebuah podcast. Bentuk podcast merupakan rekaman, tidak ada iklan, tidak ada selingan lagu yang berkepanjangan dan bisa pilih mau dengar topik apa yang sesuai, tidak perlu mengikuti jadwal seperti halnya radio. Tujuan pengabdian masyarakat ini agar menghasilkan suatu karya yang sedang di gandrungi para anak muda namun dapat memberikan juga nila kreatif, salah satu caranya adalah menghasilkan karya berupa podcast yang unik dan menarik. Metode penyampaian digunakan secara during, tetapi bisa menampilkan karya yang dapat didengar. Hasil yang diperoleh siswa memahami membuat podcast dengan diberi pemahaman perbedaan podcast dan radio, keuntungan dan memberikan beberapa cara untuk membuat podcast dari mulai persiapan membuat tema hingga ke tahap pendistribusian., kegiatan dilanjutkan dengan arahan pembuatan podcast dengan menampilkan naskah podcast dan menampilkan video tutorial menggunakan aplikasi Anchor.
\end{abstract}

Kata Kunci: Pemdampingan, Podcast, Seni Berkomunikasi

\section{PENDAHULUAN}

Dunia digital merupakan realitas yang tidak dapat dihindari, beradaptasi dengan dunia digital merupakan solusi dari evolusi komunikasi di berbagai bidang. Mulai dari Digital Image, Digital Video ataupun Digital Audio. Digital audio seperti podcast yang saat ini sedang booming diawali dengan munculnya iPod produk keluaran Apple, di kutip dari tirto.id (Zaenudin, n.d.) podcast yang merupakan perpaduan kalimat antara $i P o d$ dan Broadcasting, merupakan tayangan digital audio dengan memanfaatkan jaringan internet seperti siaran radio, namun podcast tidak memutar lagu, tetapi hanya membahas topiktopik menarik dengan berbagai episode, untuk dapat mendengarkan siaran dari podcast awalnya hanya dapat di dengar melalui iTunes. Seiring perkembangan teknologi yang semakin pesat disertai munculnya aplikasi Spotify atau Google Play Music memudahkan setiap orang untuk mendengarkan podcast dimana dan kapan saja melalui berbagai aplikasi audio streaming.

Tren podcast semakin dikenal dan saat ini podcast bukan lagi untuk aplikasi namun lebih ke sebuah program, dan dalam memproduksi podcast tidak hanya menggunakan aplikasi podcast namun saat ini podcast dapat diproduksi menggunakan aplikasi youtube atau aplikasi Achor dengan output berupa digital audio yang dapat di share ke aplikasi musik streaming. Menurut (Gogali \& Tsabit, 2020) Podcast adalah sebuah aplikasi konvergensi yang mampu menghimpun, membuat dan mendistribusikan program audio video radio pribadi secara bebas melalui newmedia serta mampu 
menghimpun format MP3, pdf, ePub, dan download melalui sindikasi sehingga dapat disatukan dalam satu wadah dan diakses banyak orang di seluruh belahan dunia. (Laila, 2021) menambahkan bahwa Podcast memiliki keunggulan karena memiliki potensi, yaitu dapat mengakses secara otomatis, penggunaan mudah dan kontrol ada di tangan pengguna atau pendengar. Selain itu, podcast dapat dibawa dan didengar kapanpun dan di manapun, serta konten ini akan selalu tersedia di wadah platform yang digunakan oleh pemilik konten.

Menurut (Geoghegan \& Klass, 2008) Podcasting itu menarik karena siapa pun bisa terlibat, mengekspresikan diri, bertukar ide, atau mengenalkan produk mereka. Apa pun yang ingin dilakukan, selalu ada tempat bagi mereka yang ingin menuangkan idenya di podcast. Podcast menempatkan kekuatan untuk berkomunikasi ke tangan individu. Ribuan orang sudah menggunakan, masingmasing memiliki keunikannya sendiri. Bahkan seseorang tidak memerlukan studio mewah atau ijin resmi dari pemerintah, yang diperlukkan hanyalah mikrofon, komputer, dan konten kreatif yang dapat dibagikan ke penjuru dunia selama terkoneksi dengan internet. (Meisyanti, 2020) menambahkan bahwa munculnya podcast tentu dapat memberikan jawaban dari kebutuhankebutuhan masyarakat yang mungkin selama ini belum sepenuhnya terpenuhi dari siaran radio.

Sebagian pengguna podcast adalah para remaja yang berada pada generasi $\mathrm{Y}$ hingga generasi $\mathrm{Z}$ yang sudah sangat tergantung dengan teknologi digital. Berdasarkan data yang diperoleh dari databoks katadata.id (Dimas Jarot Bayu, n.d.) per-Februari 2021 jumlah pendengar podcast atau rekaman audio yang dapat didengarkan dari internet di Indonesia didominasi oleh anak muda. Secara rinci $22,1 \%$ responden yang mendengarkan podcast berusia 15-19 tahun. Sebanyak $22,2 \%$ pendengar podcast lainnya berusia 20-24 tahun. Jumlah pendengar podcast mengalami penurunan seiring bertambahnya usia. Direntang usia 2529 tahun jumlah pendengar podcast sebesar $19,9 \%$ dan $15,7 \%$ pendengar podcast yang berada direntang usia 30-34 tahun.
Berdasarkan data diatas dapat ditarik kesimpulan bahwa pengaruh podcast begitu besar pada anak-anak di usia remaja, usia dimana secara fisik dan psikis sedang mengalami perkembangan dan keingintahuan yang begitu besar sehingga hal-hal baru akan dicoba. Menurut (Fakhrurrazi, 2019) Perkembangan kognitif remaja merupakan periode tertinggi dalam tahap pertumbuhan, pada periode ini remaja sudah memiliki pola berfikir sendiri dalam memecahkan masalah, para remaja sudah tidak menerima informasi apa adanya, namun informasi tersebut akan diproses serta akan mengadaptasinya dengan pemikirannya sendiri.

Para remaja yang saat ini duduk di bangku sekolah SMA merupakan pengguna aktif teknologi digital seperti padcast, banyak dari para remaja mencoba membuat podcastnya sendiri. Seperti para remaja di SMA Karya Enam Enam Jakarta. Setelah dilakukan observasi ke SMA Karya Enam Enam antusias siswa siswi begitu besar terhadap podcast, rata-rata mereka mendengarkan podcast dari channel youtube dan sebagian melalui spotify. Karena antusias siswa tersebut terhadap podcast sehingga kami melakukan pengabdian kepada masyarakat dengan judul "Pendampingan Pembuatan Podcast Kreatif Melalui Seni Berkomunikasi Efektif di SMA Karya Enam Enam Jakarta".

Diharapkan dengan adanya pendampingan terhadap remaja, khususnya Siswa SMA Karya Enam Enam sehingga dalam membuat konten podcast dapat terarah dengan baik dan menghasilkan konten podcast yang berkualitas dan membangun. Diperlukan ketelitian serta konsistensi Tim dalam mendampingi para remaja yang secara emosional dapat berubah dengan cepat. Berbagai karakter remaja diharapkan dapat mengkreasikan idenya untuk dibuat menjadi konten podcast dan dapat dibagikan ke seluruh penjuru dunia.

Tentunya tujuan dari pengabdian ini adalah 1) Untuk mengajak para siswa bagaimana cara menghasilkan suatu karya yang sedang di gandrungi para anak muda saat ini sehingga menjadi sesuatu yang memiliki nilai. Salah satu caranya adalah menghasilkan karya berupa podcast yang diharapkan para siswa dapat memiliki bakat 
diluar pelajaran sekolah; 2) Agar para siswa/i terkadang tidak memiliki tempat untuk menyalurkan bakatnya terutama dalam bidang public speaking dan content creator, terlebih pada masa pandemi seperti ini. Tim Dosen Program Studi Ilmu Komunikasi membantu para siswa/i untuk menyalurkan bakatnya melalui media digital yang memang sedang marak digunakan oleh berbagai kalangan dari segala usia, dengan memilih beberapa konten untuk dijadikan sebuah podcast. Di zaman yang serba digital ini sangat amat memungkinkan anak SMA untuk bisa membuat karya yang dapat dinikmati oleh orang lain.agar bisa dipakai atau dilakukan ketika ia lulus nanti; 3) Untuk meningkatkan minat dan bakat para siswa dalam bidang podcast yang disukai anak muda saat ini.

\section{METODE}

Sasaran dalam kegiatan ini merupakan para siswa di SMA Karya Enam Enam yang berada di wilayah Jatinegara Jakarta Timur, dalam pelaksanaan kegiatan Pengabdian Kepada Masyarakat ini, sebelumnya kami mengajukan surat permohonan untuk diberi waktu dalam melakukan kegiatan pendampingan membuat konten podcast. Sebelum menjadikan SMA Karya Enam Enam sebagai tempat pelaksanaan kegiatan Pengabdian Kepada Masyarakt, kami melakukan observasi dengan menyebar kuesioner berupa daftar pertanyaan (pre-test) yang mengarah pada tingkat pemahaman para siswa terhadap podcast. Karena masih terhalang pandemic covid-19, pelaksanaan Kegiatan Kepada Masyarakat dilaksanakan secara daring, menurut (Ramadhan et al., 2018) Pembelajaran elektronik atau disebut $e$ learning (Electronic Learning) merupakan salah satu hasil perpaduan antara pemanfaatan teknologi dengan pembelajaran. Perpaduan ini dimaksudkan untuk meningkatkan kualitas pembelajaran itu sendiri.

Saat pelaksanaan, berbagai topik menarik bagi para remaja agar dapat membuat ide menarik untuk konten podcastnya. Pengenalan aplikasi membuat podcast seperti aplikasi Achor yang merupakan aplikasi system Android bagi para siswa untuk memulai membuat konten podcast. Aplikasi achor memiliki fitur-fitur pendukung dalam membuat podcast, seperti layer untuk membuat episode dan memberi judul episode atau tema yang diangkat serta terdapat fitur mendesian poster podcast sesuai dengan tema yang diangkat.

Setelah pelatihan membuat konten podcast dan untuk mengetahui tingkat pemahaman setelah pendampingan, kami melakukan post-test kepada para siswa. Hasilnya, para siswa dapat memehami dengan baik bagaimana memanfaatkan serta mengembangkan ide agar menarik dalam membuat konten podcast. Meskipun semua kegiatan dilakukan secara daring, namun tidak menyurutkan semangat para siswa dalam mempelajari membuat konten podcast.

\section{HASIL DAN PEMBAHASAN}

Perkembangan podcast di Indonesia, sudah semakin dikenal dan dikonsumsi oleh masyarakat. Podcast menjadi salah satu medium yang berkembang pesat dalam beberapa tahun terakhir. Menurut (Hutabarat, 2020) Pemanfaatan podcast dalam berbagai bidang semakin meluas, termasuk salah satunya di bidang pendidikan/ edukasi. Penggabungan teknologi dalam pendidikan bukanlah hal yang baru. Teknologi telah memainkan peran dalam pengajaran dan pembelajaran.

Melihat perkembangan podcast melesat, maka Dosen Program Studi Ilmu Komunikasi Universitas Nasional Jakarta, mengambil inisiatif untuk memberikan Pengabdian Kepada Masyarakat pada salah satu SMA di Jakarta yaitu SMA Karya Enam-Enam Jakarta, dimana saat melakukan observasi di SMA ini masih membutuhkan pengetahuan mengenai podcast menggunakan bahasa yang komunikatif.

Menurut (Suprapto, 2018) Komunikasi merupakan sarana untuk terjalinnya hubungan antar seseorang dengan orang lain, dengan adanya komunikasi maka terjadilah hubungan sosial, karena bahwa manusia itu adalah sebagai makhluk sosial, antara yang satu dengan yang lainnya saling membutuhkan, sehingga terjadinya interaksi yang timbal 
balik. Dalam hubungan seseorang dengan orang lain tentunya terjadinya proses komunikasi itu tentunya tidak terlepas dari tujuan yang menjadi topik atau pokok pembahasan, dan juga untuk tercapainya proses penyampaian informasi itu akan berhasil apabila ditunjang dengan alat atau media sebagai sarana penyaluran informasi atau berita.

Kegiatan pengabdian kepada masyarakat dilaksanakan hari Selasa 16 Maret 2021 pukul 10.00 - 16.40 WIB melalui aplikasi whatsapp (WA) dan link zoom meeting bersama kelas XI IPS I SMA Karya Enam-Enam Jakarta. Pengabdian ini dilakukan secara daring dikarenakan belum bisa melakukan tatap muka bersama murid-murid dari SMA Karya Enam-Enam Jakarta. Kegiatan pengabdian ini diikuti oleh 19 Siswa/i kelas XI IPS I, karena kelas ini merupakan salah satu kelas yang membutuhkan pembelajaran podcast untuk berkomunikasi secara efektif.. Tim Pengabdian Kepada masyarakat yang dilakukan Dosen Program Studi Ilmu Komunikasi Universitas Nasional terdiri dari Djudjur Luciana Radjagukguk, S.Sos., M.Si., Yayu Sriwartini S.Sos, M.Si dan Agus Salim, M.I.Kom, serta dibantu mahasiswa selaku instruktur yaitu Vian Nauval Perdana dan Syarifah Nadila.

Melalui WA grup Kelas XI IPS I SMA Karya Enam-Enam Jakarta poster untuk mengikuti kegiatan pengabdian ini pun dibagikan.

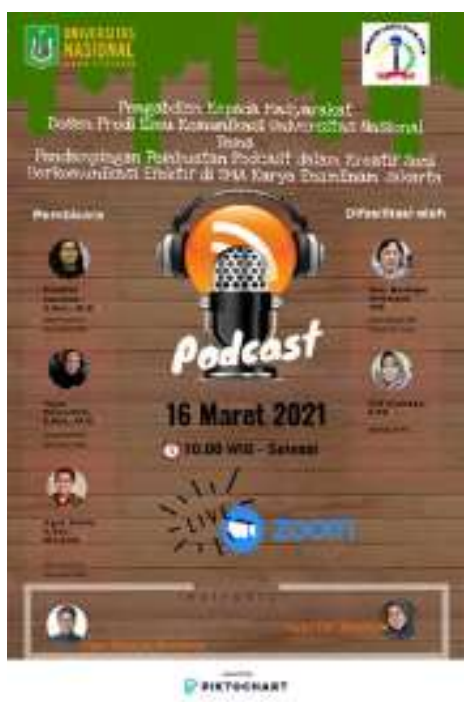

Gambar 1. (Poster Kegiatan PKM)
Sebelum melakukan pemberian materi pengabdian di hari Senin 15 Maret 2021, Tim PKM Universitas Nasional Bapak Agus Salim, membagikan pre-test terlebih dahulu. Hal ini dilakukan untuk mengetahui apakah siswa dan siswi SMA Karya Enam-Enam Jakarta sudah mengetahui atau memahami tentang media podcast. Pre-test dibagikan dengan menggunakan google-form, dan diisi semua siswa/i dari SMA Karya Enam-Enam sebanyak 19 siswa.

Keesokan harinya, 16 Maret 2021 hari pelaksanaan kegiatan pengabdian kepada masyarakat, dengan sapaan hangat dari Ibu Djudjur Luciana Radjagukguk selaku Ketua Tim Pengabdian untuk Ibu Kepala Sekolah Dra. Nurkaya Sitompul MM dan Ibu Siti Syuhada selaku Wali Kelas XI IPS I melalui grup Whatshap. Kemudian mengingatkan kepada siswa/i bahwa akan ada kegiatan Pengabdian Kepada Masyarakat melalui zoom meeting. Setelah itu link untuk mengakses zoom meeting pun dibagikan Bapak Agus tepat pukul $09.40 \mathrm{WIB}$.

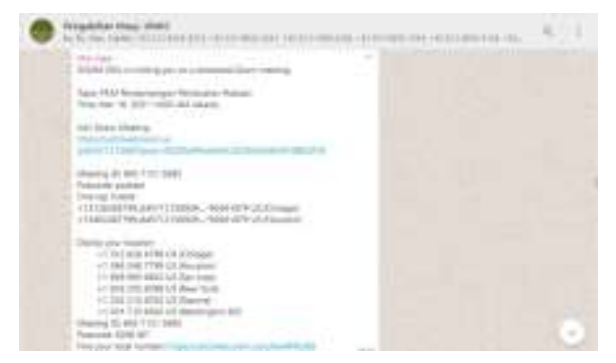

Gambar 2. (Link zoom dibagikan ke peserta)

Acara dimulai pada pukul 10.10 diawali dengan sambutan dari pihak sekolah, oleh Kepala Sekolah SMA Karya Enam-Enam Jakarta Ibu Dra. Nurkaya Sitompul, M.M,. Kemudian dari sambutan dari Tim PKM diberikan oleh Ibu Yayu Sriwartini sekaligus pembacaan doa sebelum pemaparan materi diberikan oleh Ibu Djudjur Luciana Radjagukguk.

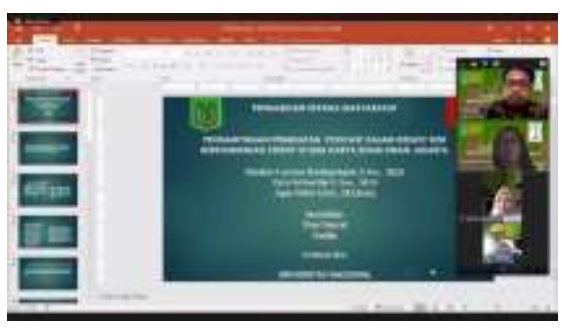




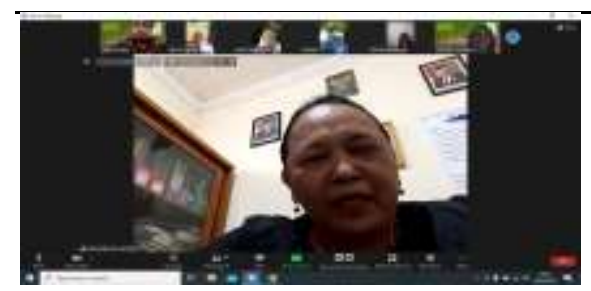

Gambar 3\&4 (Sambutan dari Pihak Sekolah dan Tim PKM)

Pada pukul 10.15 WIB dengan dihadiri oleh semua siswa/i SMA Karya Enam-Enam Jakarta kelas XI IPS I, Ibu Djudjur memberikan materi seputar dunia podcast. Melalui materi yang disampaikan, ibu Djudjur menyampaikan beberapa hal mengenai podcast, yang diantaranya adalah pengertiannya, perbedaan antara podcast dan radio, keuntungan serta menjelaskan beberapa cara untuk membuat podcast dari mulai persiapan membuat tema hingga ke tahap pendistribusian. Bahwa Podcast adalah berkas digital berupa audio yang pendengarnya diharuskan untuk mengunduh terlebih dahulu untuk bisa mendengarkan audio tersebut. Podcast ini adalah audio nonstreaming, sehingga sangat berbeda dengan radio. Podcast ini telah banyak digunakan oleh masyarakat untuk mendengarkan berita, ilmu pengetahuan, dan sharing ilmu pengetahuan yang bersifat dapat diulang. Bisa diulang, karena memang sudah diunduh diawal.

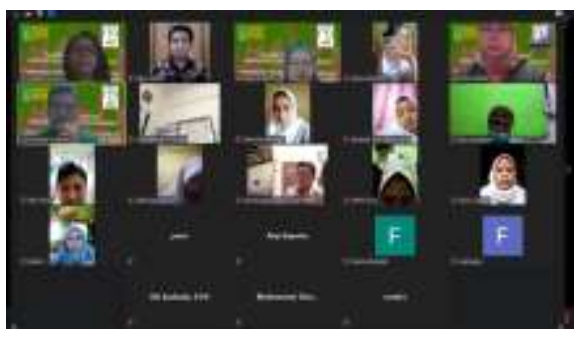

Gambar 5. (Para Peserta dan Tim PKM)

Kemudian, setelah dijelaskan berdasarkan teori, kegiatan dilanjutkan dengan arahan dari insturktur PKM yaitu Vian Nauval dan Syarifa Nadila yang menjelaskan pembuatan podcast dengan menampilkan naskah podcast dan menampilkan video tutorial menggunakan aplikasi Anchor.

Sebelum pengabdian dimulai, Ketua Tim PKM sudah terlebih dahulu memberitahu melalui grup whatshap kepada seluruh siswa/i SMA Karya Enam-Enam, untuk mendownload terlebih dahulu aplikasi Anchor, karena aplikasi ini adalah aplikasi yang dapat memudahkan siswa/i untuk mengedit sebuah podcast.

Saat menjelaskan soal praktik melalui zoom meeting, Vian dan Nadila membagikan tutorial singkat menggunakan aplikasi anchor dan memberikan contoh podcast yang sudah diedit dengan aplikasi tersebut. Setelah itu adalah praktik dari pembuatan podcast, para siswa/i diminta untuk membuat podcastnya masing-masing, kemudian hasilnya akan dikumpulkan hingga pukul 15.00 WIB dan akan dinilai oleh tim PKM. Bagi siswa/i yang membuat podcast dengan tema/penulisan, intonasi yang baik, serta pemilihan backsound yang tepat, akan dimasukkan kedalam 3 siswa/i terbaik dan mendapatkan reward dari tim PKM. Setelah zoom sesi pertama selesai, dilanjutkan setelah penilaian, tim PKM membagikan materi yang sebelumnya disampaikan lewat zoom meeting ke whats app grup, agar siswa/i dapat memahami kembali materi maupun video tutorial yang diberikan oleh tim PKM.

Beberapa jam sebelum pengumpulan, 8 siswa/i telah mengumpulkan karya podcast terbaik mereka, termasuk ibu wali kelas, ibu Siti Syuhada yang juga ikut serta dalam membuat karya podcast. Pada pukul 15.42, Bapak Agus menutup pengumpulan karya podcast siswa/i untuk dinilai oleh tim PKM, setelah itu akan diadakan kembali pada pukul 16.00 untuk menutup acara sekaligus akan ada ulasan singkat dari tim PKM terhadap karya podcast yang diberikan oleh siswa/i. Kemudian setelah diberikan ulasan, tim PKM akan mengumumkan 3 karya terbaik dari podcast yang dibuat oleh siswa/i SMA Karya Enam-Enam Jakarta.

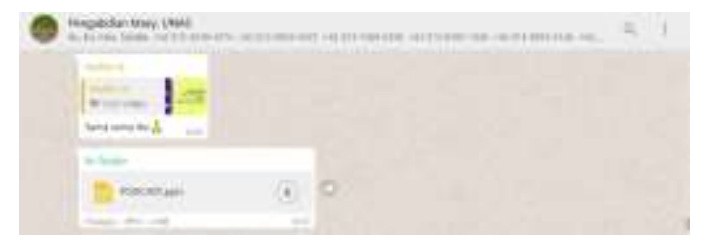




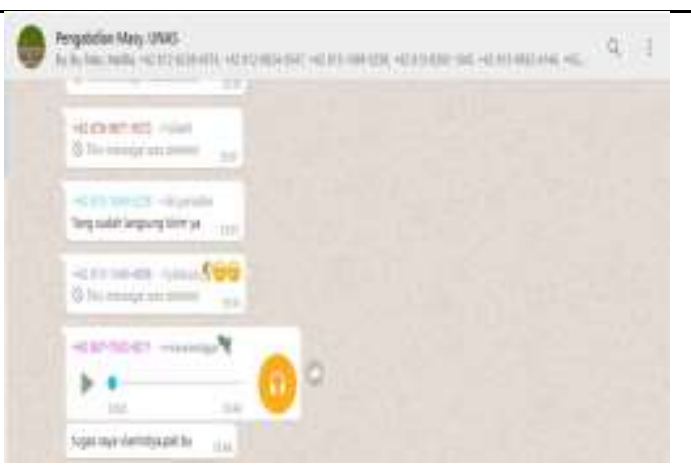

Gambar 6\&7 (Interaksi melalui Whatsapp antara siswa dan tim PKM)

Pada pukul 15.56 pak Agus kembali membagikan link zoom sesi kedua, yang dibuka oleh ibu Yayu, dan mempersilahkan Tim PKM untuk memberi ulasan terhadap podcast yang dibuat oleh siswa/i SMA Karya Enam-Enam Jakarta. Penilaian pertama dimulai dari Vian selaku instruktur, yang mengulas podcast dari Marcella, Vianindya dan Julianti siswi XI IPS I. Kemudian dilanjutkan oleh ulasan dari pak Agus yang memberikan ulasan dari Shafira dan Thio begitu selanjutanya

Setelah diberikan ulasan dari masingmasing karya yang dibuat oleh siswa/i SMA Karya Enam-Enam Jakarta, ibu Djudjur selaku ketua kegiatan PKM pada kali ini mengumumkan 3 karya terbaik yang akan mendapatkan reward dari tim PKM karena karyanya yang kreatif dan memiliki keunikan pada podcastnya. Ketiga diantaranya adalah Marcella Ananda, Vianindya, dan Eka Thio, ketiga siswa dan siswi tersebut mendapatkan reward yang akan diberikan oleh ibu Djudjur sebagai bentuk pengapresiasian dari tim PKM terhadap usaha dan daya kreatifitas yang dimiliki oleh siswa/i dari SMA Karya EnamEnam Jakarta, agar kedepannya para siswa maupun siswi memiliki bekal untuk memulai membuat podcastnya masing-masing.

Setelah sesi kedua berakhir, Pak Agus kembali membagikan link post test kepada murid-murid setelah penjelasan mengenai podcast dari ibu Djudjur dan telah dijawab oleh semua siswa/i yang berpartisipasi pada kegiatan PKM ini.

Sebagai penutup dari kegiatan PKM ini, ucapan terimakasih yang sebesar-besarnya diutarakan oleh ibu Djudjur, ibu Yayu, dan pak Agus kepada ibu kepala sekolah, ibu wali kelas, serta siswa dan siswi SMA Karya Enam-Enam yang telah megizinkan Universitas Nasional melakukan kegiatan Pengabdian Kepada Masyarakat sebagai salah satu dari Tri Dharma Pendidikan yang harus dilakukan oleh dosen dan mahasiswa perguruan tinggi.

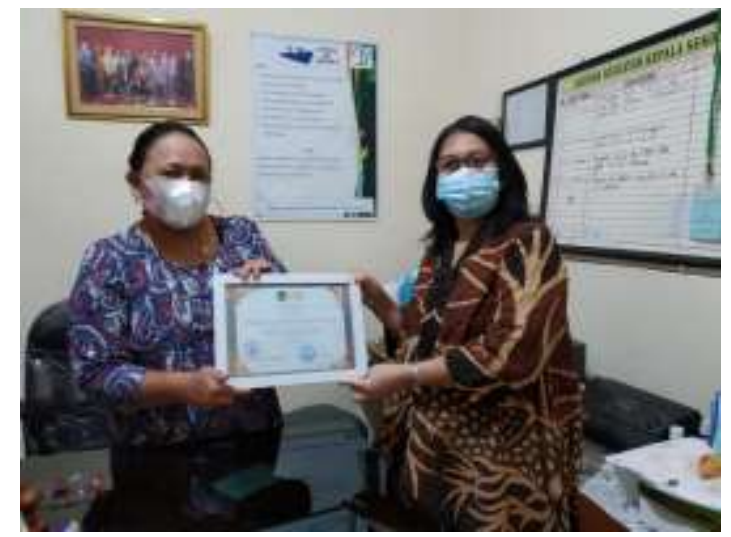

Gambar 8. (Penyerahan Sertifikat Penghargaan Sebagai tanda Terima kepada SMA Karya Enam Enam Jakarta)

\section{UCAPAN TERIMAKASIH}

Ucapan terima kasih Tim PKM Dosen Prodi Ilmu Komunikasi Universitas Nasional haturkan kepada Ketua LPPM Universitas Nasional Jakarta Prof. Dr. Ernawati Sinaga, M.S., Apt berikut jajarannya yang telah memberi dukungan moril dan finansial terhadap pengabdian ini sehingga dapat terselenggara dengan baik dan lancar. Semoga Tim PKM ini dapat memberikan hal yang terbaik untuk kemajuan anak bangsa.

\section{DAFTAR PUSTAKA}

Dimas Jarot Bayu. (n.d.). Anak Muda Dominasi Jumlah Pendengar Podcast di Indonesia. Databoks.

Fakhrurrazi. (2019). KARAKTERISTIK ANAK USIA MURAHIQAH (PERKEMBANGAN. KOGNITIF, AFEKTIF DAN PSIKOMOTORIK). $A l$ Ikhtibar: Jurnal Ilmu Pendidikan, 6(1), 573-579.

Geoghegan, M. W., \& Klass, D. (2008). Podcast solutions: The complete guide to audio and video podcasting. Apress.

Teknologi Informasi dan Komunikasi | 99 
Gogali, V. A., \& Tsabit, M. (2020). Eksistensi Radio Dalam Program Podcast Di Era Digital Konten.

Hutabarat, P. M. (2020). Pengembangan Podcast sebagai Media Suplemen Pembelajaran Berbasis Digital pada Perguruan Tinggi. Jurnal Sosial Humaniora Terapan, 2(2).

Laila, D. (2021). Inovasi Perangkat Pembelajaran Menggunakan Aplikasi Podcast. Prosiding Seminar Nasional Pembelajaran Bahasa Dan Sastra Indonesia (SemNas PBSI)-3, 7-12.

Meisyanti, W. H. K. (2020). Platform Digital Siaran Suara Berbasis On Demand (Studi Deskriptif Podcast di Indonesia). Jurnal Komunikasi Dan Media, 4(2), 191-194.

Ramadhan, R., Chaeruman, U. A., \& Kustandi, C. (2018). Pengembangan pembelajaran bauran (blended learning) di universitas negeri jakarta. Jurnal Pembelajaran Inovatif, 1(1), 37-48.

Suprapto, H. A. (2018). Pengaruh komunikasi efektif untuk meningkatkan hasil belajar mahasiswa. Khazanah Pendidikan, 11(1).

Zaenudin, A. (n.d.). Hikayat Podcast. Tirto.Id. 